\title{
Differential Regulation of Two Isoforms of the Glial Glutamate Transporter EAAT2 by DLG1 and CaMKII
}

\author{
Suzanne M. Underhill, ${ }^{1}$ David S. Wheeler, ${ }^{2}$ and Susan G. Amara ${ }^{1}$ \\ ${ }^{1}$ Laboratory of Molecular and Cellular Neuroscience, National Institute of Mental Health, National Institutes of Health, Bethesda, Maryland 20892 and \\ ${ }^{2}$ Department of Cellular Biology, School of Medicine, University of Pittsburgh, Pittsburgh, Pennsylvania 15260
}

\begin{abstract}
The gene for EAAT2, the major astrocytic glutamate transporter, generates two carrier isoforms (EAAT2a and EAAT2b) that vary at their $\mathrm{C}$ termini as a consequence of alternative RNA splicing. The EAAT2b cytoplasmic $\mathrm{C}$ terminus contains a postsynaptic density-95/Discs large/zona occludens-1 (PDZ) ligand, which is absent in EAAT2a. To understand how the distinct $\mathrm{C}$ termini might affect transporter trafficking and surface localization, we generated Madin-Darby canine kidney (MDCK) cells that stably express EGFP-EAAT2a or EGFPEAAT2b and found robust basolateral membrane expression of the EAAT2b isoform. In contrast, EAAT2a displayed a predominant distribution within intracellular vesicle compartments, constitutively cycling to and from the membrane. Addition of the PDZ ligand to EAAT2a as well as its deletion from EAAT2b confirmed the importance of the motif for cell-surface localization. Using EAAT2 constructs with an extracellular biotin acceptor tag to directly assess surface proteins, we observed significant PDZ ligand-dependent EAAT2b surface expression in cultured astrocytes, consistent with observations in cell lines. Discs large homolog 1 (DLG1; SAP97), a PDZ protein prominent in both astrocytes and MDCK cells, colocalized and coimmunoprecipitated with EAAT2b. shRNA knockdown of DLG1 expression decreased surface EAAT2b in both MDCK cells and cultured astrocytes, suggesting that the DLG scaffolding protein stabilizes EAAT2b at the surface. DLG1 can be phosphorylated by $\mathrm{Ca}^{2+} /$ calmodulin-dependent protein kinase (CaMKII), resulting in disruption of its PDZ-mediated interaction. In murine astrocytes and acute brain slices, activation of CaMKII decreases EAAT2b surface expression but does not alter the distribution of EAAT2a. These data indicate that the surface expression and function of EAAT2b can be rapidly modulated through the disruption of its interaction with DLG1 by CaMKII activation.
\end{abstract}

Key words: CaMKII; DLG1; EAAT2; glutamate transporter; PDZ

\section{Introduction}

Regulation of extracellular glutamate is critical in the CNS. Too much glutamate is toxic to cells, and too little impairs development and activity (for review, see Rothman and Olney, 1986; Olney et al., 2002; Maragakis and Rothstein, 2004). Extracellular glutamate concentrations are regulated by five excitatory amino acid transporters (EAATs; for review, see Danbolt, 2001). Each exhibits distinct kinetics, transporter-associated currents, and substrate affinities, and also cellular expression and localization profiles. The most abundant of these carriers, EAAT2, is found predominantly in astrocytes and provides the principal means for removal of glutamate from the extracellular space.

In 1997, a mouse variant of EAAT2 was described in which the last 22 amino acids of the protein are replaced by a unique se-

\footnotetext{
Received Oct. 21, 2014; revised Feb. 6, 2015; accepted Feb. 13, 2015.

Author contributions: S.M.U., D.S.W., and S.G.A. designed research; S.M.U. and D.S.W. performed research; S.M.U. and D.S.W. analyzed data; S.M.U. and S.G.A. wrote the paper.

This work was funded by NIH Grants DA07595 and MH080726, American Heart Association Grant 0525616U, and the Intramural Research Program of the NIMH. We thank Geoff Murdoch, Mads Larsen, Bozena Kutyba-Brooks, and Megan Miller for their technical assistance. The NIH Fellows Editorial Board assisted in editing this manuscript.

The authors declare no competing financial interests.

Correspondence should be addressed to Suzanne Underhill, Laboratory of Molecular and Cellular Neuroscience, National Institute of Mental Health, 35 Convent Drive, Room 3A/207 MSC3742, Bethesda, Maryland 20892-3742. E-mail: suzanne.underhill@nih.gov.

DOI:10.1523/JNEUROSCI.4365-14.2015

Copyright $\odot 2015$ the authors $\quad 0270-6474 / 15 / 355260-11 \$ 15.00 / 0$
}

quence of 11 amino acids as a product of differential splicing (Utsunomiya-Tate et al., 1997). Both rodent EAAT2 isoforms exhibit similar pharmacological profiles and transport kinetics (Utsunomiya-Tate et al., 1997; Chen et al., 2002; Sullivan et al., 2004). The original isoform, herein referred to as EAAT2a, is expressed by astrocytes throughout the brain as well as a small subset of neurons, whereas the second isoform, EAAT2b, is found in astrocytes and other glial cells (Chen et al., 2002; Reye et al., 2002; Schmitt et al., 2002; Sullivan et al., 2004; Holmseth et al., 2009).

The unique cytoplasmic C terminus of EAAT2b, but not EAAT2a, contains a sequence predicted to interact with a postsynaptic density-95/Discs large/zona occludens-1 (PDZ) domaincontaining protein. PDZ recognition sequences bind to architectural proteins and play roles in cellular targeting and scaffolding, as well as stabilization. Discs large homolog 1 (DLG1) is a PDZ protein that is found in a variety of neuronal and glial cell types as well as in the Madin-Darby canine kidney (MDCK) cell line, where it has been shown to contribute to polarity, membrane organization, and stability. We hypothesized that this protein plays a role in EAAT2b localization through PDZ binding. DLG1 interactions can be modified by activation of the $\mathrm{Ca}^{2+}$ / calmodulin-dependent protein kinase (CaMKII), posing a mechanism by which EAAT2b could by modulated (Gardoni et al., 2003). 
Using confocal microscopy and biochemical approaches in cell lines, cultured astrocytes, and brain slices, we show here that the EAAT2a isoform cycles between plasma membrane and endosomal compartments, with the major proportion of the protein found in early endosomes. In contrast, the EAAT2b isoform remains anchored at the cell surface through a direct interaction between its PDZ ligand and the PDZ protein DLG1. We developed a biotin-avidin-based cell-surface tagging assay to optically measure the cell-surface localization of glutamate transporters in primary cultures of astrocytes, and confirmed that DLG1 stabilizes the surface expression of EAAT2b, but not EAAT2a. In endogenous tissue, we found that activation of CaMKII by stimulation of AMPA/KA receptors disrupted the DLG1EAAT2b interaction and reduced the ratio of surface to intracellular EAAT2b. These data provide a novel means for dynamic regulation of different EAAT2 isoforms through interacting proteins, which could have significant effects on glutamatergic signaling in the CNS.

\section{Materials and Methods}

Cloning of EAAT2b. The rodent GLT-1b splice variant is the product of an intron read-through. The homologous sequence in the human genome revealed the genetic substrate for EAAT2b at the intron between exons 10 and 11. We used these data to clone EAAT2b from an adult human brain the RNA library. cDNAs were synthesized from commercial human brain RNA using a cDNA Cycle Kit (AM7962; Invitrogen). EAAT2bspecific sense and antisense primers (ATGGCATCTACGGAAGGT and CTATATACAAGTCTCGAT, respectively) were used to amplify EAAT2b with 25 cycles and a $58^{\circ} \mathrm{C}$ annealing temperature. The sequence of this clone was determined to be the predicted EAAT2b product, and the PCR product was subcloned into pEGFP and pcDNA3.1 vectors. These clones transported ${ }^{3} \mathrm{H}$-glutamate consistent with previous reports for the rodent isoforms with similar uptake kinetics (UtsunomiyaTate et al., 1997; Peacey et al., 2009). Addition of the EGFP tag to the $\mathrm{N}$ terminus of EAAT2a or EAAT2b did not significantly alter transporter function $\left(V_{\max }, K_{\mathrm{m}}\right.$, or dihydrokainate sensitivity). Using MDCK cells transfected with tagged or untagged transporters, we also established that addition of the EGFP tag did not alter membrane localization of the carriers as determined with immunochemistry using $\mathrm{N}$-terminal-directed antibodies that recognize both isoforms.

Cell culture. MDCK cells from American Type Culture Collection (ATCC) were maintained as described by the cell bank. Lipofectamine 2000 (catalog \#11668-027; Invitrogen) was used for transient transfections according to the manufacturer's directions. Stable cells were generated by subcloning EGFP-EAAT2 isoforms into a plasmid with an internal ribosomal entry site enabling expression of a blasticidin resistance gene as well as the EGFP-EAAT2 isoform. Stable cells were selected and maintained in DMEM-based media containing $10 \mu \mathrm{g} / \mathrm{ml}$ blasticidin. Clonal lines were also isolated, and analyses of the clonal lines were identical to those of heterogeneous cell lines. Subsequent transfection of the stable MDCK cells was performed with Magnofection (catalog \#PN30100; Oz Biosciences) according to the manufacturer's directions. Transient knockdown of DLG1 was achieved in MDCK cells and primary astrocytes with transfection of hSAP97 HuSH constructs (catalog \#TF313458; Origene).

Primary murine culture. All animal protocols were approved by the University of Pittsburgh Institutional Animal Care and Use Committee and the NIH Animal Care and Use Committee. The cortices of embryonic day 15 murine embryos were dissected from Swiss-Webster mice, following anesthesia and cervical dislocation of the timed pregnant dam. The tissue was finely triturated and plated at a density of one hemisphere per 6-25 mm coverslip coated with poly-D-lysine (100 $\mu \mathrm{g} / \mathrm{ml})$. Cultures were fed every 3-4 d with MEM containing $5 \%$ horse serum and $5 \%$ fetal bovine serum. Primary cells were transfected with NeuroMag (catalog \#NM50200; Oz Biosciences) according to the manufacturer's directions.
Biotinylation assays. MDCK cells were grown on Corning Transwell permeable supports (catalog \#07-200-166; Fisher Scientific) and incubated with sulfosuccinimidyl 2-(biotinamido) methyl-1,3-dithiopropionate (sulfo-NHS-SS-biotin; catalog \#21331, Pierce) applied to only the apical or basolateral surface for $40 \mathrm{~min}$ at $4^{\circ} \mathrm{C}$, washed, and harvested. Cell lysates were incubated with Neutravidin agarose beads (catalog \#53151; Pierce), washed, eluted in Western blot buffer, and run on a Tris-glycine gel as described below in Western blots.

Western blots. Samples were incubated with lithium dodecyl sulfate sample buffer (catalog \#NP008; Invitrogen) containing 200 mм DTT for 10 min before loading onto a 4-12\% Tris-glycine gel (catalog \#EC60385; Invitrogen). Gels were transferred to PVDF filters, blocked with $5 \%$ milk in PBS with $1 \%$ Tween 20, incubated with primary antibody overnight, washed, and incubated with an appropriate secondary antibody conjugated to HRP for $1 \mathrm{~h}$ at room temperature (Jackson ImmunoResearch). Western Lightening PluCL (catalog \#NEL 105001; PerkinElmer) was used to visualize the protein bands. Images were acquired on a ChemiDoc-It imaging system and quantified with ImageJ where applicable. We measured the band intensities across a range of protein concentrations and exposure times to establish the optimal protein concentration and to ensure that chemiluminescent exposures were within the linear range for densitometric quantification.

Immunoprecipitation. Transiently transfected cells, stable cells, and brain slices were harvested in lysis buffer (1\% Triton X-100, $150 \mathrm{~mm}$ $\mathrm{NaCl}, 5 \mathrm{~mm}$ EDTA, $50 \mathrm{~mm}$ Tris) and incubated with anti-GFPconjugated agarose (catalog \#D153-8; MBL) or 1-2 $\mu \mathrm{g}$ of primary antibody overnight at $4^{\circ} \mathrm{C}$ followed by a $2 \mathrm{~h}$ protein $\mathrm{G}$ antibody capture. Beads were subsequently washed and protein eluted in Western blot buffer for subsequent analysis.

Immmunocytochemistry. Cells were fixed in $4 \%$ paraformaldehyde at $4^{\circ} \mathrm{C}$ for $30 \mathrm{~min}$, permeablized with $0.25 \%$ Triton X-100 for $10 \mathrm{~min}$, and blocked with $5 \%$ normal goat serum (NGS) for $30 \mathrm{~min}$ before incubation with primary antibodies diluted in $5 \%$ NGS overnight at $4^{\circ} \mathrm{C}$. Primary antibodies were washed off with PBS and secondary antibodies applied in $5 \%$ NGS for $1 \mathrm{~h}$. Secondary antibodies were washed off, and the coverslips were mounted in ProLong Gold antifade reagent (catalog \#P36930; Invitrogen) for subsequent confocal examination. Antibodies used in these assays were goat anti-EAAT2 (catalog \#sc-7760; Santa Cruz Biotechnology), rabbit anti-actin (catalog \#sc-7210; Santa Cruz Biotechnology), rabbit anti-GFP (catalog \#598; MBL), rabbit anti-DLG1 (catalog \#ab3437; Abcam), mouse anti-DLG1 (RPI 197.4; Stressgen), mouse anti-EEA1 (catalog \#610457; BD Transduction Laboratories), mouse anti-GM130 (catalog \#610822; BD Tansduction Laboratories), mouse anti-Golgin-97 (CDF4; Invitrogen), mouse anti-LAMP1 (Ly1C6; Enzo Life Sciences), goat anti-PICK1 (catalog \#sc9539; Santa Cruz Biotechnology), mouse anti-PSD95 (catalog \#MA1045; Thermo Scientific), rabbit anti-Rab5 (catalog \#ab18211; Abcam), mouse anti-pSer (16B4; Santa Cruz Biotechnology), and rabbit antitransferrin receptor (catalog \#sc-9099; Santa Cruz Biotechnology).

The rabbit anti-EAAT2 antibody that we used was directed against last 85 amino acids of the $\mathrm{C}$ terminus of EAAT2a as described previously (Jacoby et al., 2000). We found that this antibody also recognized EAAT2b as assessed by Western blot of protein lysates from HEK293 cells expressing only EAAT2a or only EAAT2b. To generate an antibody specific to EAAT2a, we used a GST fusion protein of the entire C terminus of EAAT2b to remove any cross-reactive antibodies leaving behind EAAT2a epitope-specific antibodies. Specificity of the EAAT2a antibody was confirmed by Western blot.

Epifluorescent and confocal microscopy. Epifluorescent microscopy was performed on a Zeiss Axioscope and captured by an Orca digital camera. Confocal images were obtained on a Bio-Rad confocal or Olympus Fluoview 1000 microscope. Images were processed with Openlab or ImageJ software.

Quantification of surface expression in MDCK cells by confocal microscopy. Confocal images were taken of a medial plane of a section of MDCK cells immunolabled for the membrane marker E-cadherin. In ImageJ, a plot profile line was drawn across the image to obtain the density profile. Clear peaks of high intensity membrane labeling were determined to be $12 \pm 5 \mu \mathrm{m}$. Stable cell lines expressing either EGFP-EAAT2a or EGFPEAAT2b were measured in a similar fashion with the first $12 \mu \mathrm{m}$ and the 
A
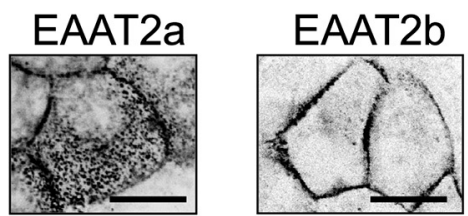

B

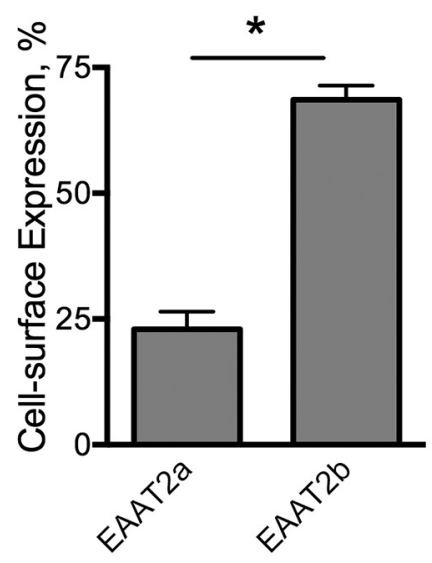

C
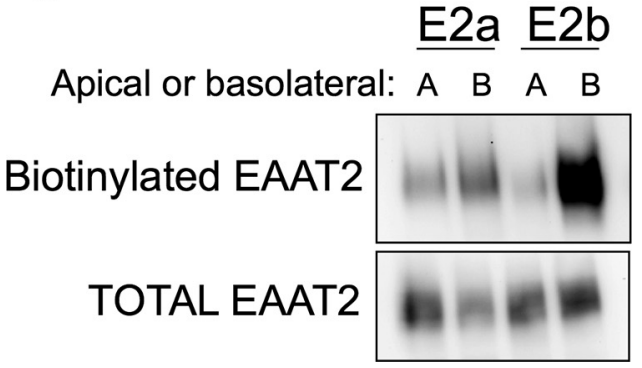

Figure 1. Localization of EAAT2a and EAAT2b in MDCK cells. $\boldsymbol{A}$, Confocal images of single horizontal sections through the middle of MDCK cells stably expressing EGFP-EAAT2a or EAAT2b. Scale bars: $50 \mu \mathrm{m}$. B. Density measurements were taken across the cells and used to quantify cell-surface expression of the isoforms (see Materials and Methods). ${ }^{*} p<0.005$ by paired $t$ test $(n=4)$. Error bars indicate SEM. C, EAAT2 is oforms from polarized MDCK cells that were biotinylated from the apical $(\boldsymbol{A})$ or basolateral $(\boldsymbol{B})$ membrane surface show membrane expression of the two carriers. EAAT2a expression is found in both the apical and basolateral membranes as described previously (Cheng et al., 2002); however, EAAT2b is found only in the basolateral membrane. Furthermore, the overall surface expression of EAAT2b is greater than that of EAAT2a.

last $12 \mu \mathrm{m}$ of the cell designated as membrane localization and the rest as cytosolic. Cell-surface expression was determined by $I_{\text {mem }} / I_{\text {Total }}$, where $I_{\text {mem }}$ is the sum intensity of the first 12 and the last $12 \mu \mathrm{m}$, and $I_{\text {Total }}$ is the cumulative intensity across the entire cell. At least three cells from three separate experiments were measured in this way for each manipulation.

Acceptor peptide-labeled EAAT2 constructs. An acceptor peptide (AP) was inserted into the second extracellular loop of EAAT2a and EAAT2b. This construct was expressed in the dual-expression vector pBUD CE4.1, where the second site contained an ER-retained BirA chimera, similar to previous studies we conducted on EAAT3 (Underhill et al., 2014). This glutamate transporter was functional even when conjugated to a labeled streptavidin. Cells transiently transfected with this AP-construct were chilled to $4^{\circ} \mathrm{C}$ in PBS, washed for 20 min, blocked with 5\% milk in PBS, incubated with a fluorophore-conjugated streptavidin protein at 1:100 for $20 \mathrm{~min}$ (Alexa 568 or Cy5), washed, and fixed in $4 \%$ paraformaldehyde for $30 \mathrm{~min}$.

An Olympus Fluoview 1000 was used in photon counting mode with an increased pinhole to capture the entirety of the cells. Regions of interest (ROIs) of the cells under investigation were measured for intensity at 488 (GFP) or 568 or 647 (Alexa-streptavidin conjugates labeling the epitopes accessible from the outside of the cell). Background subtraction was obtained by drawing ROIs around nontransfected cells. The percentage

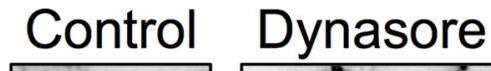

A
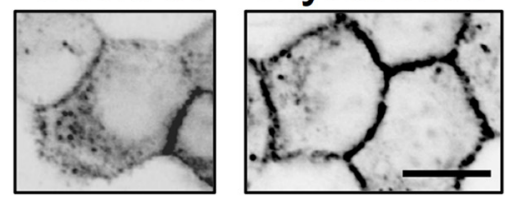

B

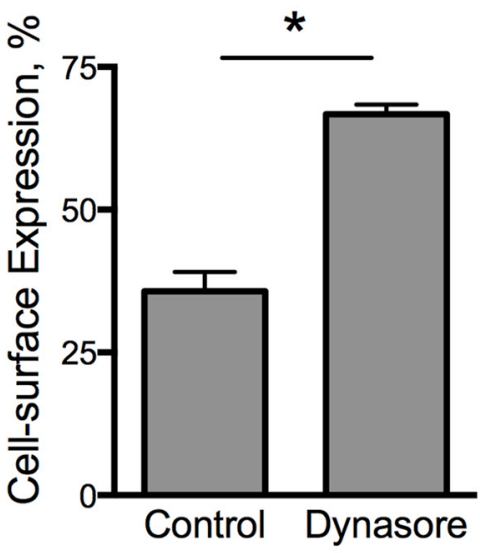

C

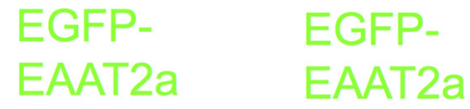

EEA1 RAB5

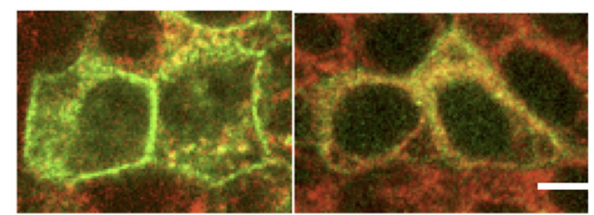

Figure 2. Localization of EAAT2a in MDCK cells. $A$, Confocal line scans through the middle of MDCK cells stably expressing EGFP-EAAT2a treated with vehicle (left) or dynasore $(80 \mu \mathrm{m}$, right). $B$, Quantitation of the effects of blocking trafficking on surface expression of the carrier. ${ }^{*} p<0.0001$ by one-way ANOVA $(n=6)$. Error bars indicate SEM. C, Confocal microscopy of immunolabeling for EEA1 and RAB5 (red) colocalize with EGFP-EAAT2a (green) in stably transfected MDCK cells. Scale bars: $50 \mu \mathrm{m}$.

of surface membrane expression was determined by the formulas $\mathrm{IG}^{\mathrm{T}}=$ $\mathrm{IG}-\mathrm{Bk}^{\text {Average }}\left(\mathrm{IG}_{\text {area }}\right)$ and surface expression $=\left(\mathrm{IG}^{\mathrm{T}}{ }_{568 / 580} / \mathrm{IG}^{\mathrm{T}}{ }_{488 / 505}\right)$, where $\mathrm{IG}^{\mathrm{T}}$ is the integration total at either the excitation emission pair of $568 / 580$ or $488 / 505$, IG is the integration of the ROI, $\mathrm{Bk}^{\text {Average }}$ is the background measurement for that image, and $\mathrm{IG}_{\text {area }}$ is the area of the selected ROI. Data were normalized to cells permeablized with $20 \mathrm{~mm}$ digitonin for 30 min such that all of the AP-biotin-conjugated EAAT2 chimeras both inside and outside the cell were labeled, indicating $100 \%$ labeling.

Acute brain slices. Adult male Swiss-Webster mice were anesthetized and, following cervical dislocation, the brains were removed and $1 \mathrm{~mm}$ coronal slices were cut in cold HBSS. Slices were rested in artificial CSF [ACSF; containing (in mM) $126 \mathrm{NaCl}, 3.5 \mathrm{KCl}, 1.3 \mathrm{MgCl}_{2}, 2 \mathrm{CaCl}_{2}, 1.2$ $\mathrm{NaH}_{2} \mathrm{PO}_{4}, 25 \mathrm{NaHCO}_{3}$, and 10 glucose] with kyurenic acid (50 $\left.\mu \mathrm{M}\right)$ for $1 \mathrm{~h}$ before experimental paradigms. Treatments were applied in ACSF bubbled with $95 \% \mathrm{O}_{2}$ and $5 \% \mathrm{CO}_{2}$.

Statistical analysis. Statistical analysis was performed with GraphPad Prism 6. All assays were performed at least three times.

\section{Results}

MDCK cells stably expressing EAAT2a or EAAT2b

To examine potential targeting and trafficking differences between EAAT2a and EAAT2b, we generated stable cell lines of MDCK cells that expressed either an EGFP-EAAT2a or an EGFPEAAT2b construct. Confocal examination of these cell lines 
A

\begin{tabular}{ll} 
EAAT2a & $\ldots$ DECKVTLAANGKSADCSVEEEPWKREK \\
EAAT2b & $\ldots$ DECKVHFPFMDIETCI \\
EAAT2a+2bCterm & $\ldots$..DECKVTLAANGKSADCSVEEEPWKREKAGSAHFPFMDIETCI \\
EAAT2a+2bPDZ & $\ldots$..DECKVTLAANGKSADCSVEEEPWKREKAGSAETCI \\
EAAT2bAPDZ & $\ldots$..DECKVHFPFMDI \\
\hline
\end{tabular}

B

Surface Expression

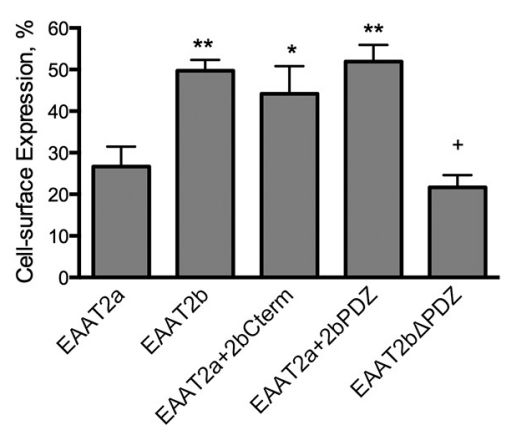

C

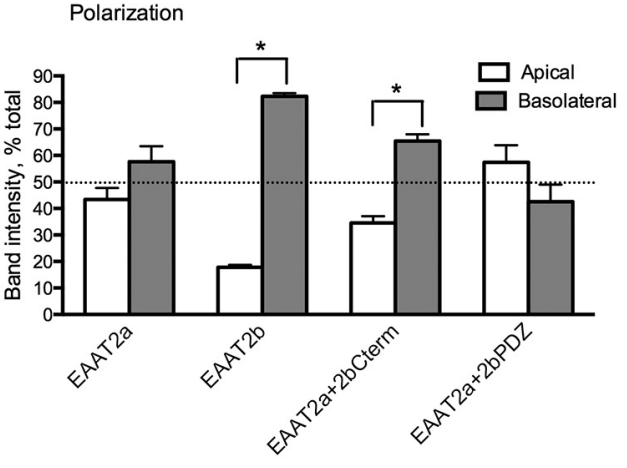

Figure 3. Role of the PDZ ligand of EAAT2b in cell-surface localization. $A$, Illustration of the mutants and chimeras used to investigate membrane localization of EAAT2b. $\boldsymbol{B}, \mathrm{MDCK}$ cells transiently transfected with EGFP-tagged mutants and chimeras were quantified for their surface membrane expression. Addition of the PDZ ligand of EAAT2b stabilizes EAAT2a at the membrane. Deletion of the PDZ ligand of EAAT2b destabilizes the surface localization of the is oform. ${ }^{*} p<0.05 ;{ }^{* *} p<0.01$ to EAAT2a; ${ }^{+} p<$ 0.01 to EAAT2b by one-way ANOVA ( $n=5$ ). Error bars indicate SEM. C, Quantitation of polarization of EAAT2a, EAATb, and the chimeras by biotinylation indicates that the PDZ ligand also dictates basolateral targeting of the EAAT2b isoform. ${ }^{*} p<0.0001$ by two-way ANOVA $(n=5)$. Error bars indicate SEM.

found only a small portion of the EGFP-EAAT2a protein on the cell surface, whereas the majority of EGFP-EAAT2b was at the surface membrane (Fig. 1 A,B). EGFP-EAAT2a MDCK cells had $23 \pm 3.5 \%$ of the total EAAT protein at the cell surface, whereas $68 \pm 2.8 \%$ of the EGFP-EAAT2b construct was localized to the surface membrane. Both isoforms exhibited similar levels of overall expression by Western blot, and similar results for surface expression were observed in two separately derived cell lines for each isoform (data not shown).

To confirm our optical quantitation, we also performed cellsurface biotinylation assays in which the apical or basolateral surfaces of the cells were exposed to a cell-impermeable biotin reagent, and then the biotinylated proteins were isolated, separated, and probed by Western blot. We found that $39 \pm 13 \%$ of EAAT $2 \mathrm{a}$ and $86 \pm 23 \%$ of EAAT2b were localized at the cell surface (Fig. 1C), consistent with data derived from the confocal optical examination. We also found that EGFP-EAAT2b was restricted to the basolateral membrane; EGFP-EAAT2b was only labeled from the basolateral surface, whereas EGFP-EAAT2a was equally accessible from either the basolateral or apical membranes demonstrating no polarization, similar to previous reports (Fig. $1 C$; Cheng et al., 2002).

\section{Characterization of EAAT2a cytosolic localization}

Because EAAT2a appeared at the cell surface of MDCK cells but was more abundant in intracellular membrane compartments, we considered the possibility that it did traffic to the cell surface, but was preferentially internalized. The dynamin inhibitor dynasore prevents internalization of proteins from the cell surface into endocytic compartments. Dynasore significantly increased the surface localization of EAAT2a (Fig. 2A,B) indicating that although EAAT2a transits to the cell surface, it is readily internalized in a dynamin-dependent fashion.

To identify the intracellular compartments in which EAAT2a is localized, we immunolabeled for a variety of markers of various intracellular compartments including Rab7, Rab5, LAMP1, Golgin, GM130, EEA1, Arf, and transferrin receptors. While EGFPEAAT2a was found in all compartments, the majority of the EGFPEAAT2a $(+)$ vesicles in MDCK cells were Rab5 $(+)$ and EEA1 $(+)$, which characterize recycling endosomes, in agreement with the ability of dynasore to inhibit internalization and effectively increase surface expression (Fig. 2C). Therefore, our results support a constitutive endocytosis of EAAT2a, whereas EAAT2b has a greater stability at the cell surface.

\section{Mutants and chimeras exploring membrane targeting of EAAT2b}

We hypothesized that the unique $\mathrm{C}$ terminus of EAAT2b most likely contains the protein motif responsible for the membrane targeting. In a previous study, an EAAT2a-EAAT3 C-terminal chimeric protein, separated by a unique polylinker sequence (AGSA), was used to investigate the trafficking and localization of EAAT3 in MDCK cells (Cheng et al., 2002). We used the same approach to identify the signal sequence for surface expression in the $\mathrm{C}$ terminus of EAAT2b.

The unique last 11 amino acids of EAAT2b were added to the $\mathrm{C}$ terminus of EGFP-EAAT2a after the polylinker (EAAT2a+2bCterm; Fig. $3 A$ ), and this chimera was used to assess surface expression of the transporter in transiently transfected MDCK cells. Confocal microscopy examination and quantification indicated that the addition of the $\mathrm{C}$ terminus of EAAT2b was sufficient to increase the localization of EAAT2a to the membrane (from $27 \pm 4.8 \%$ to $44 \pm 6.6 \%$; Fig. $3 B$ ). This sequence was also sufficient to dictate basolateral membrane expression in MDCK cells (Fig. 3C).

The last four amino acids of EAAT2b are a consensus sequence for a class I PDZ recognition sequence (E/Q T/S X V/L/I, where $\mathrm{X}$ is any amino acid; Fabre et al., 2000; Lim et al., 2002), which we hypothesized dictates membrane localization of the protein. We added just the last four amino acids of EAAT2b to EAAT2a (EAAT2a+2bPDZ; Fig. 3A) and transiently transfected this chimera into MDCK cells. EAAT2a $+2 b P D Z$ was found at the cell surface in significantly greater proportion than EAAT2a (Fig. $3 B)$. Cell-surface localization of the chimeras was confirmed in independent assays with biotinylation assays (data not shown). Addition of the PDZ ligand to EAAT2a, however, was not sufficient to polarize the transporter (Fig. $3 C$ ).

We also explored the significance of the PDZ ligand in the surface expression of EAAT2b in MDCK cells by deleting the 
last four amino acids from EAAT2b. Quantitation of confocal examination revealed that EAAT2b $\Delta 4$ was localized to the cell surface to a similar degree as EAAT $2 \mathrm{a}(27 \pm 4.8 \%$ vs $22 \pm 3.0 \%$; Fig. $3 B)$. These data indicate the PDZ ligand of EAAT2b is required for stabilization of the transporter at the cell surface.

\section{DLG1 and EAAT2b in MDCK cells}

The PDZ ligand consensus sequence of EAAT2b suggests that this transporter likely interacts with a variety of PDZ proteins. Previous reports have found that PICK1 (Bassan et al., 2008) and PSD95 (Ide et al., 1999; GonzalezGonzalez et al., 2008) can interact with this EAAT2 isoform. Astrocytes, the cells that endogenously express the greatest amount of EAAT2b, do not robustly express these two proteins. However, the PDZ protein DLG1 is found in both MDCK cells and developing astrocytes. Interestingly, DLG1 is restricted to the basolateral surface of MDCK cells (Ide et al., 1999), consistent with our observations of EAAT2b.

We observed that EGFP-EAAT2b and DLG1 colocalized in MDCK cells at the basolateral membrane, whereas EGFP-EAAT2a did not colocalize with DLG1 (Fig. 4A, B). Immunoprecipitation of EGFP-EAAT2b from these cells with an antibody directed against the EGFP-portion of the fusion proteins also pulled down DLG1, indicating a physical interaction of these two proteins (Fig. 4C). In parallel experiments, immunoprecipitation of EGFP-EAAT2a did not coimmunoprecipitate DLG1. Our results indicate a physical interaction between DLG1 and EAAT2b mediated by the unique C-terminal sequence found exclusively in this splice variant.

Because DLG1 interacts with EAAT2b and not EAAT2a, we hypothesized that decreased expression of DLG1 may alter EAAT2b localization. To decrease DLG1 expression in MDCK cells stably expressing EGFP-EAAT2b, we used shRNA plasmids for DLG1. Two separate constructs lead to a significant reduction in DLG1 expression as assessed in individual cells by immunolabeling for DLG1 (Fig. 4D). These shRNA constructs also decreased surface expression of EAAT2b from $80 \pm 3.4 \%$ down to $45 \pm 2.3 \%$ and $43 \pm 4.2 \%$ as assessed by confocal microscopy (Fig. $4 D, E$ ).

\section{Cell-surface expression of EAAT2a and EAAT2b in cultured astrocytes}

We have established that, in MDCK cells, DLG1 regulates EAAT2b membrane targeting through interaction with the transporter's unique C-terminal sequence. To demonstrate the physiological relevance of this interaction in the CNS, we examined surface expression of the glutamate transporter isoforms in primary astrocyte cultures. Astrocytes are the predominant cell type SEM.
B

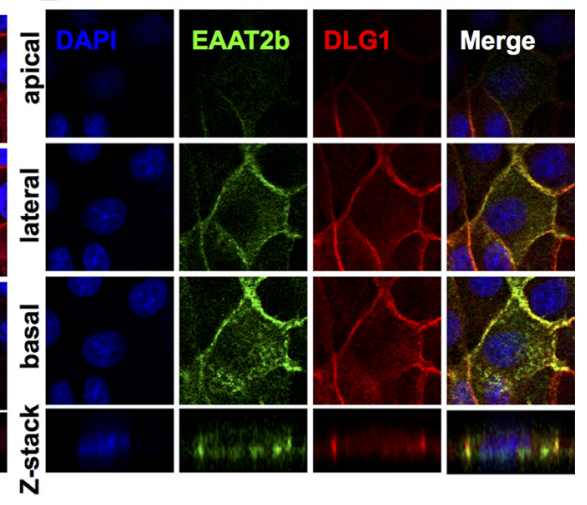

D Scrambled
DLG-1 Knockdown

\section{(1)}

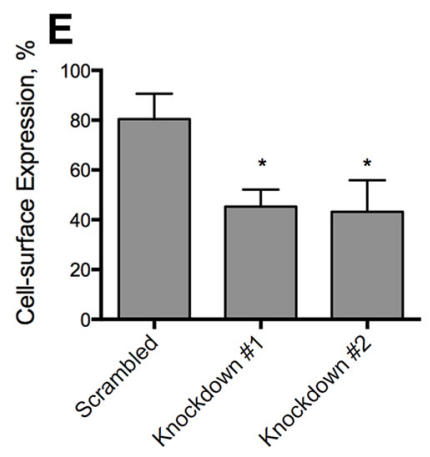

Figure 4. Localization of the PDZ protein DLG1 and EAAT2b in MDCK cells. $A$, Stable expression of EGFP-EAAT2a in MDCK cells. EAAT2a expression (green, second column) demonstrates apical (top) and basolateral expression of the carrier throughout the cell

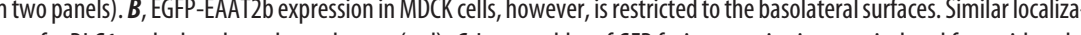
expression of knockdown constructs reveals a loss of surface expression of EAAT2b. ${ }^{*} p<0.0001$ by one-way ANOVA $(n=9)$. Error bars indicate

in which both EAAT2 isoforms are expressed in the brain. To investigate the membrane targeting of EAAT2 in astrocytes, we developed EAAT2 chimeras that could be labeled only when the carrier is expressed at the cell surface. We inserted the sequence of an AP that serves as a substrate for the Escherichia coli biotin ligase BirA (Howarth and Ting, 2008) into the large extracellular loop of EAAT2a and of EAAT2b. Furthermore, we attached an ERretention sequence to the BirA enzyme such that when it is coexpressed with an EAAT2-AP construct, the AP peptide is biotinylated within the ER, as we showed previously with EAAT3 (Underhill et al., 2014). Application of cellimpermeable, fluorophore-conjugated streptavidin to cells expressing EAAT2a-AP or EAAT2b-AP constructs results in selective labeling of the transporter proteins expressed at the cell surface. This approach is not only more selective than conventional surface biotinylation assays, but it also enables optical analyses of individual cells, rather than biochemical analysis of a population of cells.

We transiently transfected astrocytes in murine forebrain cultures with either EAAT2a-AP or EAAT2b-AP and quantified the surface expression of each isoform. EAAT2a-AP was not found at high levels at the cell surface of cultured astrocytes $(25 \pm 3.8 \%$; Fig. $5 A, B)$, whereas EAAT2b-AP was almost exclusively at the cell surface $(77 \pm 7.5 \%)$. These data are consistent with our observations in MDCK cells. 
A
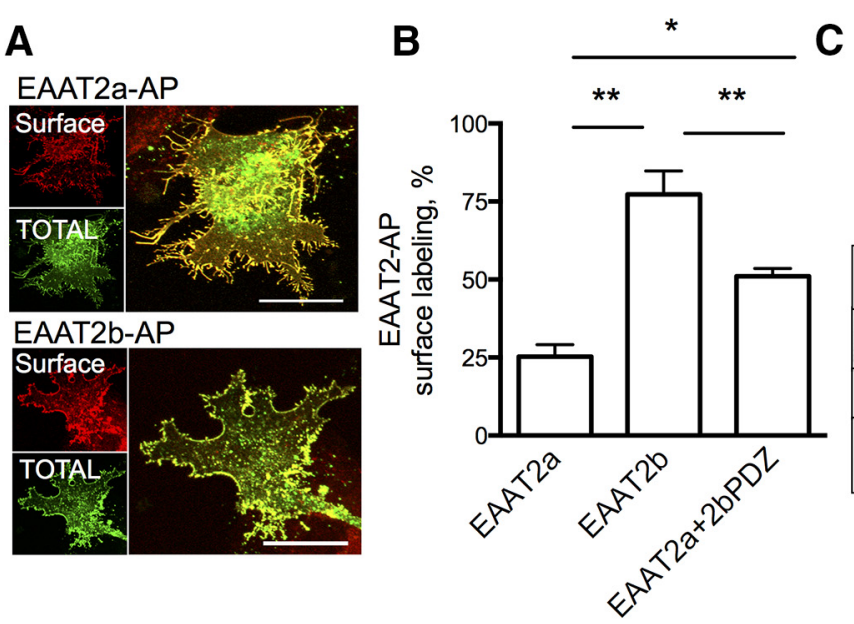

C

D

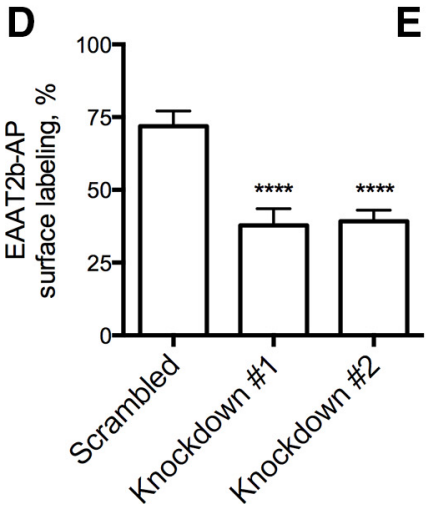

$\mathbf{E}$
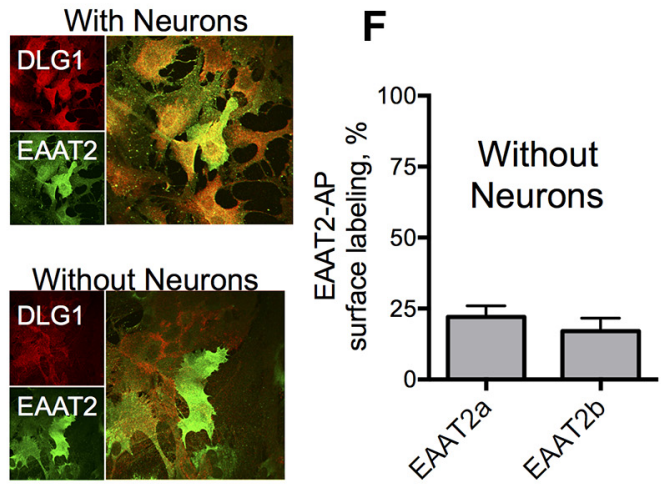

Figure 5. EAAT2b surface expression in astrocytes. $\boldsymbol{A}$, Streptavidin-Alexa 568 labeling (red) of EAAT2a-AP in primary astrocytes shows only a portion of the total protein (green) is at the cell surface. The robust labeling of EAAT2b-AP with the streptavidin-Alexa 568 , however, demonstrates that it is found almost exclusively at the cell surface (bottom). Scale bars, $50 \mu \mathrm{m}$. $\boldsymbol{B}$, Quantitation of the surface expression of these constructs by photon counting indicates that EAAT2b is found at the cell surface of primary astrocytes significantly more than EAAT2a. Addition of the PDZ ligand of EAAT2b to the EAAT2a construct can drive EAAT2a out to the cell surface. ${ }^{*} p<0.01 ;{ }^{* *} p<0.001$ by one-way ANOVA $(n=10,13,16)$. Error bars indicate SEM. C, Immunoprecipitation of EAAT2 (both isoforms, bottom) from whole-brain lysates also isolates DLG1 (top), indicating binding of these two proteins. The PDZ domain-containing proteins PICK1 and PSD95 can be detected in total brain lysates, but not in the lysates from isolated EAAT2. D, Knockdown of DLG1 in astrocytes with shRNA decreases the membrane accessibility of EAAT2b-AP. ${ }^{* * *} p<0.0001$ by one-way ANOVA $(n=11,10,20)$. Error bars indicate SEM. $E$, Astrocytes in coculture with neurons (top) immunolabel for DLG1 (red) as well EAAT2 (green). Astrocytes in culture without neurons, however, have much lower signal intensity for the PDZ protein (bottom). $\boldsymbol{F}$, Quantitation of membrane labeling of EAAT2a-AP or EAAT2b-AP in astrocytes in culture without neurons do not exhibit robust surface expression of either isoform $(n=4,3)$. Error bars indicate SEM.

\section{The PDZ ligand of EAAT2b in primary astrocytes}

To examine the role of the PDZ ligand of EAAT2b in primary astrocytes, we added the last four amino acids of EAAT2b to the EAAT2a-AP construct and assessed surface expression of this construct (EAAT2a+2bPDZ; Fig. 3A). The addition of the PDZ binding site of EAAT2b to the EAAT2a construct significantly increased the cell-surface localization of EAAT2a $+2 \mathrm{bPDZ}$ compared to EAAT2a ( $51 \pm 1.7 \%$ vs $25 \pm 3.8 \%$; Fig. $5 B)$, supporting that this interaction can regulate membrane targeting in astrocytes. These data indicate the targeting mechanisms we explored in MDCK also apply to astrocytes.

We found that DLG1 played a role in EAAT2b surface expression in MDCK cells; therefore, we investigated the role of this interaction in astrocytes and primary tissue. EAAT2 was isolated from brain lysates with an antibody directed against the $\mathrm{N}$ terminus of EAAT2. While this approach isolated both EAAT2 isoforms, it offered the advantage of not interfering with the potential PDZ interaction of the unique $\mathrm{C}$ terminus of EAAT2b.
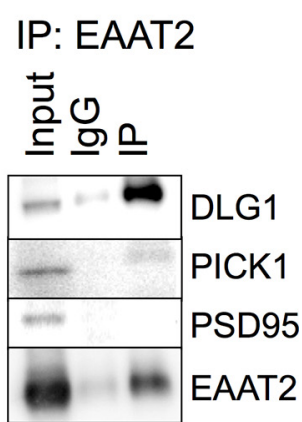

Immunoprecipitation of EAAT2 in brain lysates revealed colocalization of DLG1 with the carrier (Fig. 5C). We could not detect EAAT2 interaction with the PDZ domain-containing proteins PICK1 or PSD95, despite expression of these two proteins in the brain lysates, suggesting that the interaction with DLG1 was more robust.

We experimentally modulated DLG1 expression in cultured astrocytes with the shRNA sequences described previously. Two of these constructs led to an apparent decrease of DLG1 expression as well as a decrease in EAAT2b-AP cell-surface localization in primary astrocytes (Fig. 5D). These data in astrocytes agree with our results from the MDCK cells and indicate that DLG1 interacts with EAAT2b and facilitates membrane stability of the neurotransmitter transporter in astrocytes.

Astrocytes in coculture with cortical neurons expressed DLG1 (Fig. 5E). Interestingly, we found that astrocytes in culture without neurons did not robustly express DLG1. As predicted, EAAT2b-AP could not be found at the cell surface in astrocytes in this type of culture (Fig. 5F). These data suggest that neurons stimulate or support astrocytic expression of DLG1 that facilitates EAAT2b stabilization at the cell surface.

\section{Regulation of EAAT2b \\ membrane localization}

The anchoring of EAAT2b at the plasma membrane suggests a means for the dynamic and rapid regulation of glutamate transport through acute trafficking of the carrier. Because CaMKII activation has been demonstrated to regulate DLG1 interactions with other proteins (Schlüter et al. 2006), we hypothesized that CaMKII phosphorylation of DLG1 would destabilize its interaction with EAAT2b and lead to internalization of the carrier.

With calcium imaging, we observed that $250 \mu \mathrm{M}$ L-glutamate stimulation was sufficient to elevate intracellular $\mathrm{Ca}^{2+} 25 \%$ within $2 \mathrm{~min}$ in cultured astrocytes (data not shown). In astrocytes transiently transfected with the EAAT2b-AP construct, $30 \mathrm{~min}$ of exposure to $250 \mu \mathrm{M}$ glutamate significantly decreased surface expression of the glutamate transporter (Fig. 6A). In parallel assays, we found that EAAT2a-AP surface expression was unaffected by glutamate. These data suggest that glutamate stimulated $\mathrm{Ca}^{2+}$ dynamics could lead to regulation of EAAT2b cell-surface localization. We hypothesized that this was through CaMKII phosphorylation of DLG1, so we used the CaMKII inhibitors 2-(2hydroxyethylamino)-6-aminohexylcarbamic acid tert-butyl ester-9-isopropylpurine (CK59) and $\mathrm{N}$-[2-[[[3-(4-chlorophenyl)-2-propenyl] methylamino] methyl] phenyl]-N-(2-hydroxyethyl)-4-methoxybenzenesulphonamide (KN93). In 
primary astrocytes, the CaMKII inhibitors attenuated the glutamate-mediated loss of cell-surface expression of EAAT2b-AP (Fig. 6B). These data support that EAAT2b localization is DLG1 mediated and regulated by both glutamatergic signaling and intracellular $\mathrm{Ca}^{2+}$ changes through modulation by CaMKII phosphorylation.

To address which glutamate receptor could initiate this signaling cascade in cultured astrocytes, we treated EAAT2b-AP transfected astrocytes in culture with glutamate receptor agonists and assessed surface expression of the transporter. EAAT2b surface localization was decreased in response to kainate but not NMDA, indicating a role of AMPA/KA receptors in transporter regulation (Fig. 6C), although these agonists had no effect on EAAT2a-AP surface expression. A role for AMPA/KA receptors is further supported by the ability of the AMPA/KA antagonist NBQX to block glutamatemediated internalization of EAAT2b (Fig. $6 D)$, whereas the NMDA receptor antagonist MK801 had no significant effect. Astrocytes do express AMPA/KA receptors (Seifert and Steinhäuser, 2001), and we believe that the glutamate signaling mechanism seen here is direct, rather than through neuronal stimulation. Yano et al. (1994) also found that glutamate could activate astrocytic CaMKII through AMPA/KA receptors. Their study used astrocytes in culture alone, supporting direct stimulation of the glutamate receptors on the astrocytes leading to CaMKII activation. However, it is possible that glutamate receptor stimulation on neurons or other cell types (e.g., microglia) leads to the release of other factors that mobilize intracellular calcium and lead to CaMKII activation in astrocytes. In either case, these data show that glutamatemediated CaMKII elevation in astrocytes is sufficient to modulate EAAT2b localization.

In the mature brain, endogenous EAAT2b cell-surface expression is also regulated by calcium

To further substantiate the role of CaMKII in the modulation of EAAT2b surface localization, we next examined the regulation of endogenous EAAT2 in acute brain slice preparations. We developed antibodies that recognize EAAT2a and EAAT2b or just EAAT2a to determine which isoform was primarily affected (see Materials and Methods). Biotinylation of membranelocalized EAAT2 in acute brain slices was decreased by a $30 \mathrm{~min}$ treatment with glutamate (Fig. $7 A$ ). This was only detected in Western blots by the antibody recognizing both EAAT2 isoforms, and not by the EAAT2a-specific antibody, indicating that the majority of the change in EAAT2 surface expression is mediated by changes in EAAT2b.

To address the role of DLG1 in endogenous tissue, we immunoprecipitated EAAT2 from the acute brain lysates treated with vehicle or glutamate and assessed DLG1 binding (Fig. $7 B$ ). Exposure to glutamate resulted in $26 \pm 4 \%$ less DLG1 that coimmunoprecipitated with EAAT2.
B

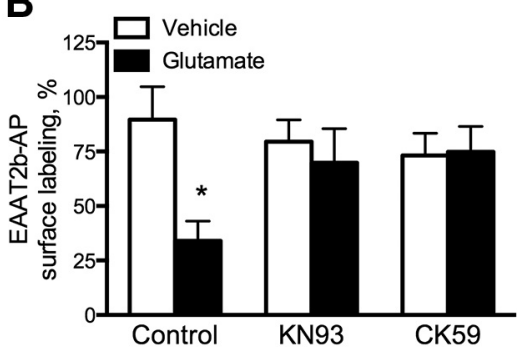

D

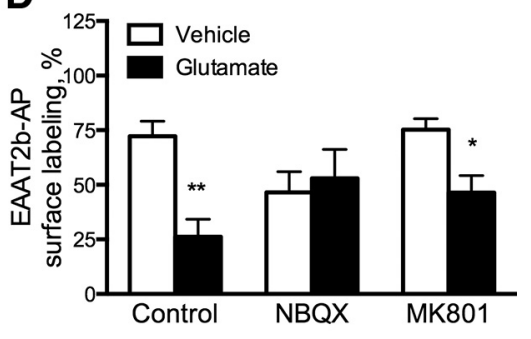

We also assessed the role of $\mathrm{Ca}^{2+}$ and CaMKII activation is acute brain slices. In calcium-free and EDTA-containing buffer, glutamate had no effect upon the surface expression of EAAT2b in acute brain slices (Fig. 7C). Furthermore, the glutamate-mediated internalization of EAAT2b was blocked by the CaMKII inhibitor KN93, indicating that the mechanism of EAAT2b internalization observed in MDCK cells as well as primary cultured astrocytes is consistent with EAAT2b surface expression in endogenous tissue.

The use of the CaMKII inhibitor in reducing glutamateinduced EAAT2b redistribution supports the role of CaMKII in EAAT2b regulation. However, we wanted to further address that glutamate receptor stimulation was coupled to CaMKIImediated phosphorylation of DLG1. CaMKII-induced modulation of DLG1 is associated with serine phosphorylation (Gardoni et al., 2003; Mauceri et al., 2004), so we immunoprecipitated DLG1 from brain lysates treated with either vehicle or glutamate and probed for phosphorylated serine residues. Immunoprecipitation of DLG1 resulted in the isolation of two species at $\sim 70$ and $\sim 120 \mathrm{kDa}$ (Fig. $7 D$, bottom panel). Glutamate treatment led to an increase in pSer associated with the larger species of immunoisolated DLG1 (Fig. 7D, top). Interestingly, the EAAT2 immunoprecipitations (Figs. 5C, 7B) resulted in isolation of only the larger species of DLG1, suggesting that EAAT2 interaction with DLG1 and regulation through phosphorylation of DLG1 occurs only with the mature DLG1 protein. We also found that glutamate-induced phosphorylation of immunoprecipitated DLG1 was blocked by the CaMKII inhibitor CK59 (Fig. 7D). These data support a model of AMPA/KA receptor-dependent CaMKII phosphorylation of 
A Biotinylated

B
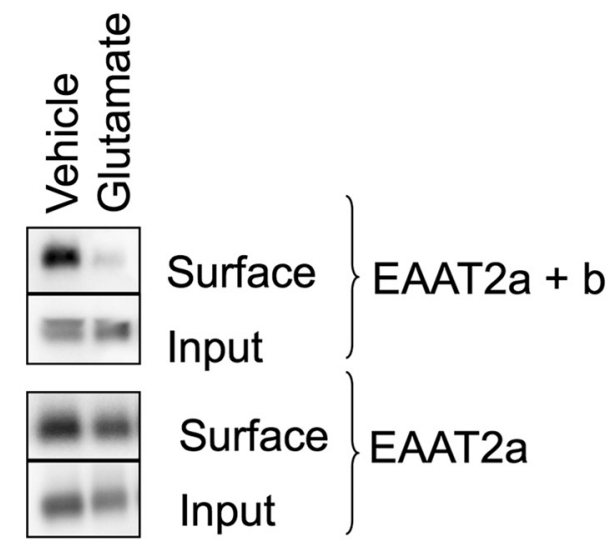

C

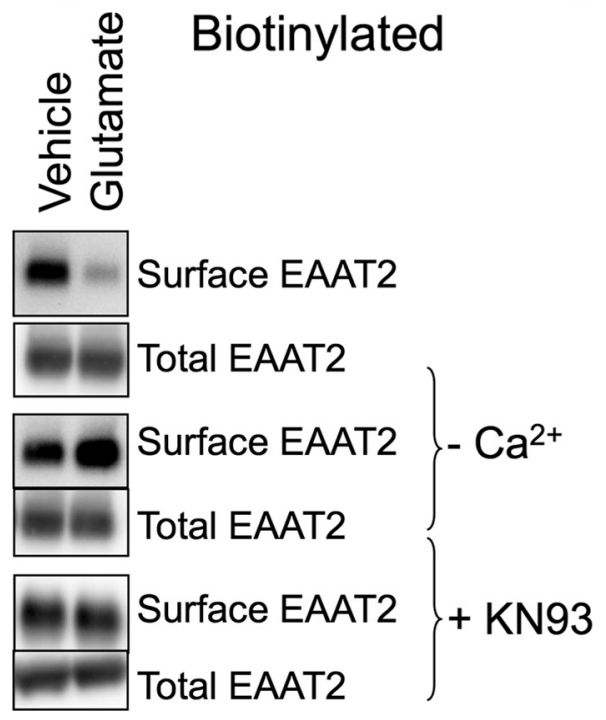

IP: EAAT2

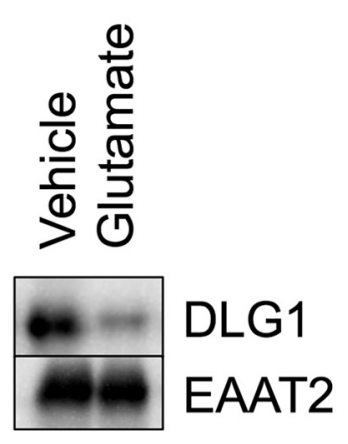

DLG1 IP

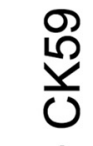

$+$

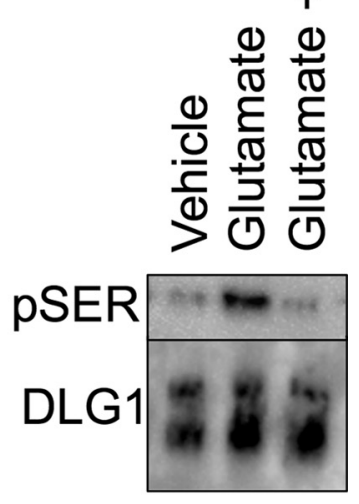

Figure 7. Endogenous EAAT2 in acute brain slices. $\boldsymbol{A}$, Biotin-accessible EAAT2 protein from acute brain slices was isolated and analyzed by Western blot. An antibody that recognizes both EAAT2 isoforms (top two panels) indicates a decrease in surface localized protein in response to glutamate ( $54 \pm 8.9 \%$ of vehicle control; $p<0.05$ by $t$ test; $n=5$ ). An antibody that recognizes only the EAAT2a isoform, however, detects no significant change in the surface expression of the carrier in response to glutamate (bottom two panels; $95 \pm 11 \%$ of vehicle control; $n=3$ ), indicating that the change in biotinylated protein is due to a change in EAAT2b localization. $\boldsymbol{B}$, Immunoprecipitation of EAAT2 with an N-terminally directed antibody coimmunoprecipitates DLG1, as also seen in the data presented in Figure 5 C. Brain slices treated with glutamate display a decrease in the amount of DLG1 that coimmunoprecipitates with EAAT2 $(26 \pm 4 \% ; p<0.05$ by paired $t$ test; $n=4)$. C, The loss of biotin-accessible EAAT2 in response to glutamate in acute brain slices was blocked by the removal of calcium or the addition of the CaMKII inhibitor KN93 during the glutamate incubation. D, DLG1 was immunoprecipitated from vehicle- or glutamate-treated acute brain slices and probed with an antibody for pSer. Blots were quantitated by densitometry of the pSer bands (top) and normalized to the total DLG1 isolated by the immunoprecipitation (bottom). Glutamate treatmentincreases thepSer signal from DLG1 ( $141 \pm 6 \%$ of control; $p<0.01$ by one-way ANOVA compared to control; $n=4)$. The CaMKll inhibitor CK59 blocks glutamate-induced phosphorylation of DLG1 (104 $\pm 7 \%$ of control; $n=4)$.

DLG1, dissociation of DLG1 and EAAT2b, and endocytosis of EAAT2b (Fig. 8).

\section{Discussion}

Here we demonstrate that the PDZ protein, DLG1, interacts with the $\mathrm{C}$ terminus of the glutamate carrier isoform EAAT2b in both epithelial cells and astrocytes to maintain the transporter at the cell surface. Increases in intracellular calcium and activation of CaMKII leads to a dissociation of DLG1 from PDZ ligand containing proteins, including EAAT2b, thus providing a rapid mechanism for modulating glutamate transporter surface expression and activity in response to extracellular signals. A second isoform EAAT2a, which arises from differential RNA splicing events, resides transiently at the plasma membrane and traffics more rapidly to and from the cell surface, establishing a dynamic, constitutively cycling pool of carriers with the potential for rapid mobilization (Fig. 8).

\section{The role of DLG1 in EAAT2b surface expression}

We addressed the significance of DLG1 in EAAT2b membrane stabilization with shRNA knockdown of the PDZprotein DLG1 in MDCK cells (Fig. $4 D, E)$ and primary cultured astrocytes (Fig. 5D) and found that depletion of DLG1 decreased EAAT2b surface expression. Interestingly, we also observed that astrocytes cocultured with cortical neurons express DLG1, but DLG1 is undetectable in astrocytes in the absence of neurons (Fig. 5E). As predicted, in isolated astrocytes that do not express DLG1, the biotin-tagged transporter EAAT2b-AP could not be found at the cell surface (Fig. 5F), whereas in astrocyte-neuron cocultures, we observed robust surface expression of EAAT2b in astrocytes (Fig. $5 A, B)$. These data suggest that neurons provide factors that stimulate and support astrocytic expression of DLG1, which in turn serves as a scaffold to stabilize EAAT2b at the cell surface. Although the neuron-astrocyte signal that stimulates DLG1 expression remains undefined, it reveals a feature of astrocyte cultures that could be critical for interpreting and comparing data from different in vitro model systems.

\section{Multimerization and \\ EAAT2 isoforms}

Based on crystal structures of the archael EAAT2 homolog, $\mathrm{GLT}_{\mathrm{Ph}}$, and other studies of subunit interactions in EAATs, glutamate transporters exist as trimers (Yernool et al., 2003, 2004; Gendreau et al., 2004; Jiang et al., 2011). Further data indicate that different EAAT isoforms can form heteromeric complexes (Nothmann et al., 2011), and there is compelling evidence that EAAT2a and EAAT2b comultimerize, both by fluorescence resonance energy transfer (FRET) and coimmunoprecipitation experiments (Gonzalez-Gonzalez et al., 2009; Peacey et al., 2009; Gebhardt et al., 2010). This heteromeric multimerization facilitates indirect interaction of the EAAT2a isoform with a PDZ protein through EAAT2b (Gonzalez-Gonzalez et al., 2008, 2009). However, these studies did not go further to examine the functional consequences of this interaction. 
We developed an acute brain slice preparation in which to investigate the regulation of EAAT2a and EAAT2b endogenously expressed within glial cells. Data from this approach suggest that the endogenous EAAT2b pool that is sensitive to calcium and CaMKII activation does not robustly affect the localization of the insensitive EAAT2a isoform (Fig. 7). This suggests that endogenous EAAT2a-EAAT2b multimerization may not affect the constitutive membrane cycling of the predominant EAAT2a isoform. However, this assay was performed on coronal brain slices from mature mouse brains and there are indications that the actual ratio of EAAT2a to EAAT2b changes throughout development (Chen et al., 2002; Holmseth et al., 2009), in specific anatomical locations (Chen et al., 2002), during learning paradigms (Fraticelli-Torres et al., 2010), and under pathophysiological conditions (Yi et al., 2005; Dumont et al., 2013). In each of these examples, the indirect regulation of EAAT2a surface expression by interaction with EAAT2b suggests a potential mechanism for DLG1/CaMKII-mediated modulation of glutamate dynamics. A more detailed examination of EAAT2a-EAAT2b multimerization may address these issues.

\section{Polarization of EAAT2a and EAAT2b}

Confocal examination and biotinylation of MDCK cells indicates that EAAT2a and EAAT2b differ not only in cell-surface expression, but also in polarization. EAAT2a appears to be expressed on all cellular membranes, whereas EAAT2b exhibits a strong preference for the basolateral cell surface of MDCK cells (Figs. $3 C, 4 A, B$ ). Polarization of EAAT2b is distinct from membrane retention and requires the entire $C$ terminus and not just the PDZ ligand (Fig. $3 B, C$ ). The primary focus of this study was to explore the role of the PDZ ligand of EAAT2b in cell-surface localization; however, the distinct polarization that we observed for this carrier may also be important to astrocyte physiology. Astrocytes migrate in response to inflammatory signals and under these circumstances have a distinct polarized face. Interestingly, DLG1 has been found on the leading edge of migrating astrocytes, highlighting the role of the PDZ protein in polarization in these cells (EtienneManneville et al., 2005). The role of polarization in mature, static astrocytes is unclear, but a marked concentration of glutamate transporters has been noted in astrocytic processes enveloping synapses, suggesting a type of polarization in these cells (Danbolt, 2001). Furthermore, EAAT2 has been found in astrocytic endfeet that interact with blood vessels to actively transport glutamate past the bloodbrain barrier (Schreiner et al., 2013). The signal sequence in the $\mathrm{C}$ terminus of EAAT2b that dictates its polarization in these structures may be important to astrocyte physiology.

\section{Potential impact of EAAT2b redistribution}

Our observation that EAAT2b internalizes in response to glutamate could be viewed as counterintuitive; however, it is consistent with a previous report showing that glutamate release leads to increased diffusion and redistribution of astrocytic transporters away from synaptic sites (Murphy-Royal et al., 2015). Redistribution of EAAT2b in response to activation of astrocyte signaling pathways could serve a number of func- tions. For example, it has been proposed that EAATs can be found closely associated with metabotropic receptors and thus may serve to limit receptor desensitization (Desai et al., 1995; Huang and Bergles, 2004). When the transporters are inhibited, baseline glutamate concentrations are sufficient to desensitize the receptors and effectively limit signaling. Alternatively, the regulated internalization of EAAT2b in astrocytes could contribute to adaptive mechanisms involved in strengthening glutamatergic transmission. Endocytosis of the transporter would increase extracellular glutamate concentrations, resulting in enhanced receptor activation during synaptic activity. Consistent with this possibility, selective inhibition of the glial glutamate transporters in hippocampal slices enhances the response of mGluR1 $\alpha$ in neighboring interneurons (Huang et al., 2004). Thus, the precise localization and redistribution of transporters in astrocytes in response to glutamate could provide a means to regulate receptor sensitivity and/or activation.

The mechanism of internalization of EAAT2b by CaMKII provides a means to redistribute and potentially concentrate carriers in distinct compartments of the astrocyte membrane, and the endocytosis of EAAT2b demonstrated in this study could be the first step in longer-term remodeling. However, it is important to note that molecules other than glutamate may be the physiological regulators of EAAT2b membrane localization, and any signal that activates CaMKII could result in internalization of EAAT2b through the mechanism presented in this study, including TNF $\alpha$ (Defer et al., 2007). Consistent with this idea, we have observed that TNF $\alpha$ decreases membrane localization of EAAT2b-AP in cultured astrocytes (data not shown).

\section{Regulation of EAAT2b by CaMKII}

Our data demonstrate that DLG1 interacts with the C terminus of EAAT2b and stabilizes the transporter at the plasma membrane, most likely through direct interaction of the $\mathrm{C}$ terminus PDZ ligand on the carrier to the well-established PDZ domain of DLG1. Previous studies have reported that the PDZ domain of DLG1 can bind the PDZ ligands of glutamate receptor subunits (Leonard et al., 1998; Gardoni et al., 2003; Rumbaugh et al., 2003; Schlüter et al., 2006) and the potassium channel KV4.2 (Gardoni et al., 2007) that anchors these transmembrane proteins within a submembrane scaffold that maintains them at synaptic membranes. The interaction of NR2A, GluR1, and KV4.2 with DLG1 are each sensitive to intracellular calcium levels through direct phosphorylation of DLG1 by CaMKII (Gardoni et al., 2003, 2007; Schlüter et al., 
2006). Within the PDZ-domain of DLG1, the serine at position 232 can be phosphorylated by CaMKII, and this phosphorylation disengages the PDZ ligand-PDZ domain interaction and disperses the proteins (Gardoni et al., 2003). We found that activation of CaMKII through AMPA/KA receptor stimulation can also modulate the surface expression of EAAT2b in astrocytes, most likely through a similar mechanism involving DLG1 phosphorylation and disruption of the PDZ interaction. Thus, CaMKII activation offers a rapid means of modulating glutamatergic activity through changing the cell-surface expression of EAAT2b. In contrast, EAAT2a constitutively cycles to and from the cell surface in astrocytes and is not subject to this regulated cycling by CaMKII activation. In this way the differential regulation of EAAT2a and EAAT2b not only insures a basal capacity of uptake by EAAT2a, but also provides a means to dynamically alter glutamate uptake in response to extracellular signals through the regulated surface localization of EAAT2b.

\section{References}

Bassan M, Liu H, Madsen KL, Armsen W, Zhou J, Desilva T, Chen W, Paradise A, Brasch MA, Staudinger J, Gether U, Irwin N, Rosenberg PA (2008) Interaction between the glutamate transporter GLT1b and the synaptic PDZ domain protein PICK1. Eur J Neurosci 27:66-82. Medline

Chen W, Aoki C, Mahadomrongkul V, Gruber CE, Wang GJ, Blitzblau R, Irwin N, Rosenberg PA (2002) Expression of a variant form of the glutamate transporter GLT1 in neuronal cultures and in neurons and astrocytes in the rat brain. J Neurosci 22:2142-2152. Medline

Cheng C, Glover G, Banker G, Amara SG (2002) A novel sorting motif in the glutamate transporter excitatory amino acid transporter 3 directs its targeting in Madin-Darby canine kidney cells and hippocampal neurons. J Neurosci 22:10643-10652. Medline

Danbolt NC (2001) Glutamate uptake. Prog Neurobiol 65:1-105. CrossRef Medline

Defer N, Azroyan A, Pecker F, Pavoine C (2007) TNFR1 and TNFR2 signaling interplay in cardiac myocytes. J Biol Chem 282:35564-35573. CrossRef Medline

Desai MA, Burnett JP, Mayne NG, Schoepp DD (1995) Cloning and expression of a human metabotropic glutamate receptor 1 alpha: enhanced coupling on co-transfection with a glutamate transporter. Mol Pharmacol 48:648-657. Medline

Dumont AO, Hermans E, Goursaud S (2013) Differential regulation of the glutamate transporter variants GLT-1a and GLT- $1 \mathrm{~b}$ in the cortex and spinal cord of transgenic rats expressing hSOD1. Neurochem Int 63:61-68. CrossRef Medline

Etienne-Manneville S, Manneville JB, Nicholls S, Ferenczi MA, Hall A (2005) Cdc42 and Par6-PKCzeta regulate the spatially localized association of Dlg1 and APC to control cell polarization. J Cell Biol 170: 895-901. CrossRef Medline

Fabre S, Reynaud C, Jalinot P (2000) Identification of functional PDZ domain binding sites in several human proteins. Mol Biol Report 27:217224. CrossRef

Fraticelli-Torres AI, Matos-Ocasio F, Thompson KJ (2010) Glutamate transporters are differentially expressed in the hippocampus during the early stages of one-day spatial learning task. Ethn Dis 20:S1-28-32. Medline

Gardoni F, Mauceri D, Fiorentini C, Bellone C, Missale C, Cattabeni F, Di Luca M (2003) CaMKII-dependent phosphorylation regulates SAP97/ NR2A interaction. J Biol Chem 278:44745-44752. CrossRef Medline

Gardoni F, Mauceri D, Marcello E, Sala C, Di Luca M, Jeromin A (2007) SAP97 directs the localization of Kv4.2 to spines in hippocampal neurons: regulation by CaMKII. J Biol Chem 282:28691-28699. CrossRef Medline

Gebhardt FM, Mitrovic AD, Gilbert DF, Vandenberg RJ, Lynch JW, Dodd PR (2010) Exon-skipping splice variants of excitatory amino acid transporter-2 (EAAT2) form heteromeric complexes with full-length EAAT2. J Biol Chem 285:31313-31324. CrossRef Medline

Gendreau S, Voswinkel S, Torres-Salazar D, Lang N, Heidtmann H, DetroDassen S, Schmalzing G, Hidalgo P, Fahlke C (2004) A trimeric quater- nary structure is conserved in bacterial and human glutamate transporters. J Biol Chem 279:39505-39512. CrossRef Medline

Gonzalez-Gonzalez IM, Garcia-Tardon N, Cubelos B, Gimenez C, Zafra F (2008) The glutamate transporter GLT1b interacts with the scaffold protein PSD-95. J Neurochem105:1834-1848. Medline

Gonzalez-Gonzalez IM, Garcia-Tardon N, Gimenez C, Zafra F (2009) Splice variants of the glutamate transporter GLT1 form hetero-oligomers that interact with PSD-95 and NMDA receptors. J Neurochem110:264-274.

Holmseth S, Scott HA, Real K, Lehre KP, Leergaard TB, Bjaalie JG, Danbolt NC (2009) The concentrations and distributions of three C-terminal variants of the GLT1 (EAAT2; slc1a2) glutamate transporter protein in rat brain tissue suggest differential regulation. Neuroscience 162:1055-1071. CrossRef Medline

Howarth M, Ting AY (2008) Imaging proteins in live mammalian cells with biotin ligase and monovalent streptavidin. Nat Protoc 3:534-545. CrossRef Medline

Huang YH, Bergles DE (2004) Glutamate transporters bring competition to the synapse. Curr Opin Neurobiol 14:346-352. CrossRef Medline

Huang YH, Sinha SR, Tanaka K, Rothstein JD, Bergles DE (2004) Astrocyte glutamate transporters regulate metabotropic glutamate receptor-mediated excitation of hippocampal interneurons. J Neurosci 24:4551-4559. CrossRef Medline

Ide N, Hata Y, Nishioka H, Hirao K, Yao I, Deguchi M, Mizoguchi A, Nishimori H, Tokino T, Nakamura Y, Takai Y (1999) Localization of membraneassociated guanylate kinase (MAGI)-1/BAI-associated protein (BAP) 1 at tight junctions of epithelial cells. Oncogene 18:7810-7815. Medline

Jacoby RA, Wiechmann AF, Amara SG, Leighton BH, Marshak DW (2000) Diffuse bipolar cells provide input to OFF parasol ganglion cells in the macaque retina. J Comp Neurol 416:6-18. CrossRef Medline

Jiang J, Shrivastava IH, Watts SD, Bahar I, Amara SG (2011) Large collective motions regulate the functional properties of glutamate transporter trimers. Proc Natl Acad Sci U S A 108:15141-15146. CrossRef Medline

Leonard AS, Davare MA, Horne MC, Garner CC, Hell JW (1998) SAP97 is associated with the alpha-amino-3-hydroxy-5-methylisoxazole-4propionic acid receptor GluR1 subunit. J Biol Chem 273:1951819524. CrossRef Medline

Lim IA, Hall DD, Hell JW (2002) Selectivity and promiscuity of the first and second PDZ domains of PSD-95 and synapse-associated protein 102. J Biol Chem 277:21697-21711. CrossRef Medline

Maragakis NJ, Rothstein JD (2004) Glutamate transporters: animal models to neurologic disease. Neurobiol Dis 15:461-473. CrossRef Medline

Mauceri D, Cattabeni F, Di Luca M, Gardoni F (2004) Calcium/calmodulindependent protein kinase II phosphorylation drives synapse-associated protein 97 into spines. J Biol Chem 279:23813-23821. CrossRef Medline

Murphy-Royal C, Dupuis JP, Varela JA, Panatier A, Pinson B, Baufreton J, Groc L, Oliet SH (2015) Surface diffusion of astrocytic glutamate transporters shapes synaptic transmission. Nat Neurosci 18:219-226. CrossRef Medline

Nothmann D, Leinenweber A, Torres-Salazar D, Kovermann P, Hotzy J, Gameiro A, Grewer C, Fahlke C (2011) Hetero-oligomerization of neuronal glutamate transporters. J Biol Chem 286:3935-3943. CrossRef Medline

Olney JW, Wozniak DF, Farber NB, Jevtovic-Todorovic V, Bittigau P, Ikonomidou C (2002) The enigma of fetal alcohol neurotoxicity. Ann Med 34:109-119. CrossRef Medline

Peacey E, Miller CC, Dunlop J, Rattray M (2009) The four major N- and C-terminal splice variants of the excitatory amino acid transporter GLT-1 form cell surface homomeric and heteromeric assemblies. Mol Pharmacol 75:1062-1073. CrossRef Medline

Reye P, Sullivan R, Pow DV (2002) Distribution of two splice variants of the glutamate transporter GLT-1 in the developing rat retina. J Comp Neurol 447:323-330. CrossRef Medline

Rothman SM, Olney JW (1986) Glutamate and the pathophysiology of hypoxicischemic brain damage. Ann Neurol 19:105-111. CrossRef Medline

Rumbaugh G, Sia GM, Garner CC, Huganir RL (2003) Synapseassociated protein-97 isoform-specific regulation of surface AMPA receptors and synaptic function in cultured neurons. J Neurosci 23: 4567-4576. Medline

Schlüter OM, Xu W, Malenka RC (2006) Alternative N-terminal domains of PSD-95 and SAP97 govern activity-dependent regulation of synaptic AMPA receptor function. Neuron 51:99-111. CrossRef Medline

Schmitt A, Asan E, Lesch KP, Kugler P (2002) A splice variant of glutamate 
transporter GLT1/EAAT2 expressed in neurons: cloning and localization in rat nervous system. Neuroscience 109:45-61. CrossRef Medline

Schreiner AE, Durry S, Aida T, Stock MC, Ruther U, Tanaka K, Rose CR, Kafitz KW (2013) Laminar and subcellular heterogeneity of GLAST and GLT-1 immunoreactivity in the developing postnatal mouse hippocampus. J Comp Neurol 522:204-224. CrossRef.

Seifert G, Steinhäuser C (2001) Ionotropic glutamate receptors in astrocytes. Prog Brain Res 132:287-299. CrossRef Medline

Sullivan R, Rauen T, Fischer F, Wiessner M, Grewer C, Bicho A, Pow DV (2004) Cloning, transport properties, and differential localization of two splice variants of GLT-1 in the rat CNS: implications for CNS glutamate homeostasis. Glia 45:155-169. CrossRef Medline

Underhill SM, Wheeler DS, Li M, Watts SD, Ingram SL, Amara SG (2014) Amphetamine modulates excitatory neurotransmission through endocytosis of the glutamate transporter EAAT3 in dopamine neurons. Neuron 83:404-416. CrossRef Medline
Utsunomiya-Tate N, Endou H, Kanai Y (1997) Tissue specific variants of glutamate transporter GLT-1. FEBS Lett 416:312-316. CrossRef Medline

Yano S, Fukunaga K, Ushio Y, Miyamoto E (1994) Activation of Ca2+/ calmodulin-dependent protein kinase II and phosphorylation of intermediate filament proteins by stimulation of glutamate receptors in cultured rat cortical astrocytes. J Biol Chem 269:5428-5439. Medline

Yernool D, Boudker O, Folta-Stogniew E, Gouaux E (2003) Trimeric subunit stoichiometry of the glutamate transporters from Bacillus caldotenax and Bacillus stearothermophilus. Biochemistry 42:12981-12988. CrossRef Medline

Yernool D, Boudker O, Jin Y, Gouaux E (2004) Structure of a glutamate transporter homologue from Pyrococcus horikoshii. Nature 431:811-818. CrossRef Medline

Yi JH, Pow DV, Hazell AS (2005) Early loss of the glutamate transporter splice-variant GLT-1v in rat cerebral cortex following lateral fluidpercussion injury. Glia 49:121-133. CrossRef Medline 